\title{
BMJ Open Association between breastfeeding support and breastfeeding rates in the UK: a comparison of late preterm and term infants
}

\author{
Sarah Rayfield, ${ }^{1,2}$ Laura Oakley, ${ }^{1,3}$ Maria A Quigley ${ }^{1}$
}

To cite: Rayfield S, Oakley L, Quigley MA. Association between breastfeeding support and breastfeeding rates in the UK: a comparison of late preterm and term infants. BMJ Open 2015;5: e009144. doi:10.1136/ bmjopen-2015-009144

\section{- Prepublication history} and additional material is available. To view please visit the journal (http://dx.doi.org/ 10.1136/bmjopen-2015009144).

Received 26 June 2015 Revised 18 September 2015 Accepted 14 October 2015

\section{(1) crossanat}

${ }^{1}$ Policy Research Unit in Maternal Health and Care, National Perinatal

Epidemiology Unit, University of Oxford, Oxford, UK

${ }^{2}$ Nuffield Department of Population Health, University of Oxford, Oxford, UK

${ }^{3}$ Department of

Non-communicable Disease

Epidemiology, London

School of Hygiene and

Tropical Medicine,

London, UK

Correspondence to

Dr Sarah Rayfield;

Sarah.rayfield@doctors.org.uk

\section{ABSTRACT}

Objective: To explore the association between breastfeeding support and breastfeeding among late preterm (gestation 34-36 weeks) and term (gestation $\geq 37$ weeks) infants.

Methods: Secondary analysis of the UK 2010 Infant Feeding Survey. Logistic regression was used to determine the association of breastfeeding support with breastfeeding at 10 days and 6 weeks in late preterm and term infants.

Results: The study included 14525 term and 579 late preterm infants. A total of 11729 infants initiated breastfeeding (11 $292(81.1 \%)$ term, $437(79.4 \%)$ late preterm infants, $p=0.425)$. Of these, $9230(84.3 \%)$ term and $365(85.6 \%)$ late preterm infants were breastfeeding at 10 days $(p=0.586)$; of these 7547 $(82.0 \%)$ term and $281(75.4 \%)$ late preterm infants were still breastfeeding at 6 weeks $(p=0.012)$. Mothers who reported receiving contact details for breastfeeding support groups had a higher likelihood of breastfeeding late preterm (adjusted ORs, aOR 3.14, $95 \% \mathrm{Cl} 1.40$ to 7.04 ) and term infants (aOR 2.24, $95 \% \mathrm{Cl} 1.86$ to 2.68$)$ at 10 days and term infants at 6 weeks (aOR 1.83, 95\% $\mathrm{Cl} 1.51$ to 2.22). Those who reported that they did not receive enough help with breastfeeding in hospital had a lower likelihood of breastfeeding late preterm at 10 days and term infants at 10 days and 6 weeks, compared to those who reported having enough help.

Conclusions: Receiving sufficient help with breastfeeding in hospital and the contact details for breastfeeding support groups is associated with breastfeeding term infants up to 6 weeks and late preterm infants at 10 days.

\section{INTRODUCTION}

Infants born between $34+0$ and $36+6$ weeks gestation are increasingly described as late preterm'. This highlights that despite their size and weight often being similar to term infants, they are physiologically relatively immature, ${ }^{2}$ with higher rates of morbidity and mortality ${ }^{2-4}$ compared to term infants. Breastfeeding protects against gastrointestinal $^{5-10}$ and respiratory illnesses ${ }^{9-12}$

\section{Strengths and limitations of this study}

- Secondary data analysis of a large national survey and one of the first studies to specifically compare the role of breastfeeding support, as perceived by the mother, in late preterm and term infants.

- Mothers were oversampled from the most deprived quintile of the Index for Multiple Deprivation in the original survey. The use of survey weights in this study allowed for the oversampling and also non-response, thereby ensuring adequate representation of this difficult to reach group.

- An extensive range of confounding factors were considered and adjusted for in the analysis including ethnicity, socioeconomic status, marital status and age mother left full time education. This is important as breastfeeding is known to be associated with a number of sociodemographic factors.

- This study is retrospective in design with the Infant Feeding Survey being completed by parental self-report of both breastfeeding support and breastfeeding duration when the infants were approximately 6 weeks old, therefore, the results of this analysis may be limited by recall bias or potentially a socially desirable response bias and it is not possible to infer causality.

- Infants classified as breastfeeding in this study are likely to represent a very heterogeneous group, ranging from primarily breastfed infants to infants receiving minimal breastmilk.

and is associated with better cognitive development in childhood, particularly in preterm infants. ${ }^{13}$ Despite potential benefits for this group, late preterm infants experience lower rates of breastfeeding initiation and continuation compared to term infants. ${ }^{1415}$

The WHO and UK Departments of Health recommend exclusive breastfeeding for the first 6 months. ${ }^{16}$ Although $81 \%$ of UK mothers initiate breastfeeding, this rapidly 
drops to $55 \%$ at 6 weeks and $34 \%$ at 6 months, with less than $1 \%$ of infants exclusively breastfeeding at 6 months. ${ }^{17}$ Predictors of breastfeeding success in highincome countries include non-white ethnicity, ${ }^{18}{ }^{19}$ increasing maternal age ${ }^{20-22}$ and higher age of leaving full time education. ${ }^{20}{ }^{22}$ Similar sociodemographic patterns have been shown in late preterm infants ${ }^{23}$ although in general, evidence regarding breastfeeding in late preterm infants is limited.

Breastfeeding support is recommended in the Baby Friendly Hospital initiative (BFHI) ${ }^{24}$ and can comprise professional or lay support, educational or supportive interventions, or any combination of these. Breastfeeding support is more likely to be effective if it is proactive, delivered face to face and provided on an ongoing basis. ${ }^{25}$ However, the majority of studies evaluating the effects of breastfeeding support are restricted to healthy term infants or they evaluate the impact of breastfeeding given in the neonatal unit (NNU) to preterm infants. ${ }^{26}$ In the UK, at the time of the survey, support and advice about breastfeeding is usually provided initially by midwives during pregnancy. Advice may also be offered during antenatal classes, either provided through the NHS, or by third sector organisations. After the birth of an infant, breastfeeding support would initially be provided by midwives or midwife care assistants within a hospital setting. Most hospitals offer breastfeeding support sessions including breastfeeding counsellors. At around day 10 of life, care of the mother and infant is transitioned from midwifery to the health visiting team who continue to care for the child until the age of 5 years. Health visitors can offer guidance and support with breastfeeding. In addition, breastfeeding support groups including counsellors and peer support are often provided in children's centres or by third sector organisations the details of which would be provided to the mother by either the midwife or health visitor.

Given the increased vulnerability in the late preterm population and higher likelihood of breastfeeding difficulties, it is particularly necessary to understand which breastfeeding support is the most effective for this group. The objective of this study was to investigate the association between different forms of breastfeeding support on breastfeeding rates at 10 days and 6 weeks in late preterm and term infants.

\section{METHODS}

\section{Study design}

This was a cross-sectional study involving secondary analysis of data from the UK 2010 Infant Feeding Survey (IFS) ${ }^{17}$ The IFS is undertaken every 5 years in order to monitor breastfeeding prevalence and infant feeding practices. In 2010 , it comprised a nationally representative unclustered sample of 30760 infants with oversampling of mothers from the most deprived quintile of the Index for Multiple Deprivation (IMD). The use of weights in the survey analysis allowed for this oversampling and differential non-response according to mother's age and IMD, and aims to makes the survey representative of the UK population. The IFS included three postal questionnaires assessing feeding status of the infant at 6-10 weeks, 4-6 months and 8-10 months. They were completed by self-report, usually by the mother of the infant. The IFS questionnaire in 2010 was based on the previous version and was piloted in all four countries of the UK prior to being rolled out. The original survey was approved by the Ethics committee, Department of Health Sciences at the University of York.

This study primarily used data from the first questionnaire, which a total of 15724 mothers responded to (51\% response rate). This questionnaire contained 150 questions over 39 pages (see web appendix 1: Questionnaire) including questions on breastfeeding duration and breastfeeding support accessed. For infants who were less than 6 weeks at the first questionnaire, data were also used from the second questionnaire (3382 infants). The analysis was restricted to singleton births born at more than 34+0 weeks gestation (15 104 infants) (see web appendix 2: flow chart). Only those infants who initiated breastfeeding were included in the analysis of breastfeeding at 10 days. Only those still breastfeeding at 10 days were included in the subsequent analysis at 6 weeks.

\section{Measures}

Breastfeeding support variables were identified from questions in the stage 1 questionnaire ${ }^{27}$ (box 1 ). Specific variables were chosen to reflect different times at which support was given, from antenatal and immediately following delivery, to subsequent support given at home. To fully explore the association of breastfeeding support, these variables were also chosen to reflect the different nature of support ranging from direct support such as skin to skin contact to provision of information. Outcomes included the prevalence of breastfeeding at 10 days and 6 weeks. Infants were classified as having initiated breastfeeding if any breastmilk (direct or expressed) was received after birth, even if only once. ${ }^{28}$ Subsequently, infants were classified as breastfed if they were receiving any breastmilk as part of their nutrition, regardless of other fluids or solids. This included infants who were regarded as 'partial breastfeeding', but also those who were exclusively breastfed (when no other food or drink, not even water, except breastmilk is received). Outcome timepoints were chosen as the transition from midwife care to the health visiting team occurs at 10 days postpartum and it is accepted that breastfeeding can take 6 weeks to be fully established.

Potential confounding factors were divided into sociodemographic characteristics and pregnancy and delivery characteristics. Sociodemographic characteristics included the infant's ethnicity, maternal age, marital status, age at leaving full time education, socioeconomic status (as defined by maternal occupation using the NSSEC system ${ }^{29}$ ), and IMD $^{30}$ as a measure of area-based 


\section{Box 1 Breastfeeding support questions*}

- During pregnancy, were you taught how to position your baby for breastfeeding and how to attach your baby to your breast?

- Did you receive 'skin to skin' contact with your baby immediately after delivery?

- How soon following delivery was your baby put to your breast?

- In the days after birth, were you given advice on how to recognise if your baby was getting enough milk?

- Were you offered support for feeding problems encountered in the hospital or birth centre?

- While you were in the hospital, birth centre or unit, did you get enough help and support with feeding your baby?

- Since leaving the hospital, birth centre or unit, were you given details of voluntary organisations or community support groups which helps new mothers with infant feeding?

- Are you aware of the National Breastfeeding helpline?

- Since leaving the hospital, birth centre or unit, were you given help or information for any feeding problems encountered at home?

- In the first 6 weeks, did you receive breastfeeding support from a voluntary organisation, peer supporter, national breastfeeding helpline or breastfeeding support group?

- In the first 6 weeks, did you receive breastfeeding support from a health professional (midwife, midwife support worker, nurse, nursery nurse, health care assistant, health visitor, children's health clinic or doctor)?

- In the first 6 weeks, did you receive breastfeeding support from a media source (books, leaflets, magazines, television, radio or the internet)?

${ }^{\star}$ Answers were based on parental recall at approximately 6 weeks postpartum.

deprivation. Pregnancy and delivery characteristics included parity (subdividing multiparous women by previous breastfeeding experience of more or less than 6 weeks), type of delivery, admission to the NNU, length of stay in hospital, gestation at delivery, antenatal feeding intention and peer feeding behaviour (whether they had known other mothers during pregnancy and which feeding methods they had used).

\section{Statistical analysis}

Logistic regression was used to calculate ORs for the association between breastfeeding support and breastfeeding at 10 days and 6 weeks. Analysis of the factors associated with breastfeeding at 10 days was based on those who initiated breastfeeding. Similarly, the analysis of breastfeeding at 6 weeks was based on those who were breastfeeding at 10 days. The analysis was conducted separately for late preterm $(34+0-36+6$ weeks $)$ and term $(>37+0$ weeks) infants and was performed in stages due to large numbers of variables: first the sociodemographic variables (model $\mathrm{A})$, then the antenatal and delivery characteristics (model B), and finally the breastfeeding support variables (model $\mathrm{C}$ ). At each stage, variables that were not statistically significant $(p>0.05)$ were removed from the model. The remaining statistically significant variables within models $\mathrm{A}$ and $\mathrm{B}$ were combined with model $\mathrm{C}$ with further dropping of variables that were not statistically significant as necessary. Antenatal feeding intention and the peer feeding variables were included in the model as a priori confounders, regardless of their $p$ value as they are recognised as being highly predictive of subsequent feeding behaviour. ${ }^{21}$ 3133 The final multivariable model for breastfeeding at 10 days included any remaining statistically significant variables from each of models $\mathrm{A}, \mathrm{B}$ and $\mathrm{C}$ in addition to these two variables.

These final regression models for the late preterm and term infants at 10 days were then used as the respective models for breastfeeding at 6 weeks. Outcomes are presented as adjusted ORs (aOR), with 95\% CIs. STATA V.13 was used to conduct the analysis with 'survey commands' to take account of the weighted sample. All percentages and ORs are presented as weighted values, whereas frequencies are unweighted values.

\section{RESULTS}

There were 15104 singletons born at more than 34 weeks gestation, of which 14525 (95.9\%) were full term and $579(4.1 \%)$ were late preterm. Overall, mothers of late preterm infants had a younger age distribution, were more likely to be from a non-white ethnic group and were more deprived than mothers of fullterm infants (table 1). In addition, late preterm infants were less likely to have been born by normal vaginal delivery (NVD), were more likely to be admitted to the NNU $(43.4 \%$ vs $4.4 \%$ of term infants, $\mathrm{p}<0.001)$ and had a longer length of stay in hospital when compared to term infants (table 1 ).

Overall, 11729 mothers initiated breastfeeding, including $11292(81.1 \%)$ term infants and $437(79.4 \%)$ late preterm infants $(p=0.425)$. The rates of breastfeeding declined rapidly in both groups: $9230(68.4 \%)$ term infants and $365(67.9 \%)$ late preterm infants were still being breastfed at 10 days; and $7547(56.1 \%)$ term infants and $281(51.2 \%)$ late preterm infant were still being breastfed at 6 weeks. Of those who initiated breastfeeding, $9230(84.3 \%)$ term infants and 365 (85.6\%) late preterm were still breastfeeding at 10 days $(p=0.586)$. Of those breastfeeding at 10 days, late preterm infants were significantly less likely to be breastfeeding at 6 weeks than term infants (281 (75.4\%) versus $7547(82.0 \%)$, unadjusted OR $0.67,95 \%$ CI 0.49 to $0.92, \mathrm{p}=0.012$ ).

Among term and late preterm infants, breastfeeding at 10 days was higher among mothers in managerial professions and in those living in the least deprived areas (table 2). In term infants there were clear patterns of increasing rates of breastfeeding with increasing maternal age and with increasing levels of maternal education. White mothers had the lowest rates of breastfeeding at 10 days and 6 weeks among all infants, whereas mothers with previous breastfeeding experience consistently had the highest rates (table 3). 
Table 1 Comparison between late preterm and term population $\dagger$

\begin{tabular}{|c|c|c|c|c|c|}
\hline \multirow[b]{2}{*}{ Variable } & \multicolumn{2}{|c|}{$\begin{array}{l}\text { Late preterm infants } \\
(34-36+6)\end{array}$} & \multicolumn{2}{|c|}{$\begin{array}{l}\text { Term infants } \\
(37+)\end{array}$} & \multirow[b]{2}{*}{ p Value } \\
\hline & $\mathbf{N}$ & Per cent & $\mathbf{N}$ & Per cent & \\
\hline Total & 579 & 4.1 & 14525 & 95.9 & \\
\hline \multicolumn{6}{|l|}{ Maternal age } \\
\hline$<20$ & 40 & 8.7 & 546 & 5.2 & $0.027^{*}$ \\
\hline $20-24$ & 97 & 21.5 & 2095 & 18.3 & \\
\hline $25-29$ & 155 & 26.9 & 4051 & 28.1 & \\
\hline $30-34$ & 158 & 24.2 & 4691 & 29.0 & \\
\hline $35+$ & 126 & 18.6 & 3092 & 19.5 & \\
\hline \multicolumn{6}{|l|}{ Ethnicity } \\
\hline White & 488 & 81.5 & 12882 & 86.2 & $0.026^{*}$ \\
\hline Asian/Asian British & 40 & 11.3 & 615 & 6.8 & \\
\hline Black/Black British & 13 & 4.0 & 362 & 4.1 & \\
\hline Other & 13 & 3.2 & 291 & 2.9 & \\
\hline \multicolumn{6}{|l|}{ Marital status } \\
\hline Single & 91 & 16.4 & 2046 & 15.1 & 0.526 \\
\hline Married/living together & 482 & 83.6 & 12334 & 84.9 & \\
\hline \multicolumn{6}{|l|}{ Age mother left full time education } \\
\hline$<16$ & 124 & 24.1 & 2447 & 19.0 & 0.056 \\
\hline $17-18$ & 158 & 29.2 & 4088 & 29.6 & \\
\hline$>18$ & 291 & 46.7 & 7869 & 51.5 & \\
\hline \multicolumn{6}{|l|}{ NSSEC } \\
\hline Managerial & 199 & 30.0 & 5643 & 35.2 & $<0.001^{\star \star \star}$ \\
\hline Intermediate & 103 & 18.3 & 2942 & 19.9 & \\
\hline Routine + manual & 159 & 25.2 & 3759 & 27.2 & \\
\hline Never worked/not classified & 118 & 26.6 & 2181 & 17.7 & \\
\hline \multicolumn{6}{|l|}{ IMD quintile } \\
\hline Most deprived & 172 & 36.4 & 3297 & 27.1 & $<0.001^{\star \star *}$ \\
\hline 2 & 113 & 22.4 & 2930 & 22.4 & \\
\hline 3 & 101 & 13.6 & 2914 & 18.7 & \\
\hline 4 & 100 & 14.9 & 2748 & 16.4 & \\
\hline Least deprived & 92 & 12.5 & 2262 & 15.4 & \\
\hline \multicolumn{6}{|l|}{ Parity } \\
\hline Primiparous & 321 & 58.6 & 7050 & 51.3 & $0.002^{\star \star}$ \\
\hline Multiparous who breastfed $<6$ weeks & 142 & 22.1 & 3480 & 21.3 & \\
\hline Multiparous who breastfed $>6$ weeks & 16 & 19.3 & 3995 & 27.4 & \\
\hline \multicolumn{6}{|l|}{ Type of delivery } \\
\hline NVD & 322 & 61.2 & 8808 & 63.5 & $<0.001^{\star \star \star}$ \\
\hline Instrumental & 51 & 7.9 & 2066 & 13.8 & \\
\hline Caesarean & 204 & 31.0 & 3620 & 22.6 & \\
\hline \multicolumn{6}{|l|}{ Neonatal unit admission } \\
\hline Yes & 258 & 43.4 & 658 & 4.4 & $<0.001^{\star \star \star}$ \\
\hline No & 321 & 56.6 & 13867 & 95.5 & \\
\hline \multicolumn{6}{|l|}{ Length of stay in hospital } \\
\hline$<12 \mathrm{~h}$ & 16 & 3.3 & 1849 & 14.6 & $<0.001^{\star \star \star}$ \\
\hline $12-24 \mathrm{~h}$ & 52 & 8.9 & 3690 & 26.7 & \\
\hline $1-2$ days & 83 & 14.7 & 3829 & 24.8 & \\
\hline 3-7 days & 309 & 51.3 & 3918 & 24.6 & \\
\hline$>7$ days & 89 & 15.6 & 143 & 1.0 & \\
\hline Not born in hospital & 3 & 0.9 & 390 & 3.0 & \\
\hline
\end{tabular}

\section{Breastfeeding support in term infants}

In univariable analysis, all of the breastfeeding support questions in box 1 were significantly associated with breastfeeding term infants at 10 days and all except questions 10 and 11 were significantly associated with breastfeeding at 6 weeks. In multivariable analysis, mothers of term infants who reported being given advice on recognising if their infant was getting enough milk 
Table 2 Descriptive analysis* of sociodemographic characteristics

\begin{tabular}{|c|c|c|c|c|}
\hline \multirow{2}{*}{$\frac{\text { Variable }}{\text { Gestation }}$} & \multicolumn{2}{|c|}{ Breastfeeding at 10 days (\%) } & \multicolumn{2}{|c|}{ Breastfeeding at 6 weeks (\%) } \\
\hline & $34-36+6$ & $37+$ & $34-36+6$ & $37+$ \\
\hline N (sample size) & $365(437)$ & 9230 (11 292) & $281(365)$ & $7547(9230)$ \\
\hline \multicolumn{5}{|l|}{ Maternal age (years) } \\
\hline$<20$ & 85.7 & 64.7 & 61.2 & 63.0 \\
\hline $20-24$ & 76.3 & 76.1 & 68.1 & 70.7 \\
\hline $25-29$ & 82.5 & 82.9 & 69.1 & 80.7 \\
\hline $30-34$ & 92.2 & 88.8 & 84.1 & 85.9 \\
\hline $35+$ & 92.6 & 89.1 & 84.0 & 87.0 \\
\hline \multicolumn{5}{|l|}{ Ethnicity } \\
\hline White & 84.5 & 82.1 & 70.1 & 79.4 \\
\hline Asian/Asian British & 80.8 & 93.2 & 87.1 & 89.8 \\
\hline Black/Black British & 98.1 & 98.9 & 88.2 & 95.7 \\
\hline Other & 100 & 91.0 & 90.8 & 88.4 \\
\hline \multicolumn{5}{|l|}{ Marital status } \\
\hline Single & 88.0 & 75.8 & 62.2 & 71.4 \\
\hline Married/living together & 85.7 & 85.4 & 77.0 & 83.1 \\
\hline \multicolumn{5}{|c|}{ Maternal age at leaving full time education } \\
\hline$<16$ & 85.1 & 71.9 & 64.8 & 71.8 \\
\hline $17-18$ & 74.2 & 79.0 & 65.4 & 74.5 \\
\hline$>18$ & 92.9 & 90.0 & 82.9 & 87.0 \\
\hline \multicolumn{5}{|l|}{ NSSEC } \\
\hline Managerial & 92.3 & 89.4 & 82.6 & 85.9 \\
\hline Intermediate & 81.9 & 81.7 & 58.8 & 80.2 \\
\hline Routine+manual & 88.4 & 78.2 & 72.7 & 74.8 \\
\hline Never worked/not classified & 77.3 & 84.5 & 79.6 & 84.4 \\
\hline \multicolumn{5}{|l|}{ IMD quintile } \\
\hline Most deprived & 80.2 & 80.3 & 73.0 & 82.4 \\
\hline 2 & 87.6 & 84.2 & 82.5 & 81.1 \\
\hline 3 & 87.2 & 82.8 & 67.8 & 80.8 \\
\hline 4 & 88.9 & 88.6 & 76.4 & 82.9 \\
\hline Least deprived & 91.2 & 87.7 & 80.4 & 83.0 \\
\hline
\end{tabular}

were more likely to be breastfeeding at 10 days (aOR $1.24,95 \%$ CI 1.05 to 1.46 ) (table 4) compared to mothers reporting that they were not given this advice. They were also more likely to be breastfeeding at 10 days if they reported being given the contact details of community support groups (aOR 2.24, 95\% CI 1.86 to 2.68), if they were aware of the national breastfeeding helpline (aOR 1.29, 95\% CI 1.08 to 1.53), or if they used support from community support groups (aOR 1.30, 95\% CI 1.01 to 1.68 ) when compared to mothers who did not report each of these breastfeeding support activities. Mothers who reported no feeding problems in hospital were more likely to be breastfeeding at 10 days (aOR 1.57, 95\% CI 1.29 to 1.91 ) than women who reported feeding problems and had received help in hospital; among the women who experienced feeding problems in hospital, maternal report of receiving help was not associated with breastfeeding at 10 days. In contrast, breastfeeding at 10 days was less likely in mothers who reported either no feeding problems at home (aOR $0.62,95 \%$ CI 0.50 to 0.77 ) or feeding problems with no support (aOR 0.58 , $95 \%$ CI 0.42 to 0.80$)$ compared with mothers who reported receiving help for feeding problems at home.
Mothers who used support from healthcare professionals were less likely to be breastfeeding at 10 days (aOR 0.63, $95 \%$ CI 0.50 to 0.79 and 6 weeks (OR $0.71,95 \%$ CI 0.57 to 0.88 ) compared to those who did not use support. Out of those who had encountered feeding problems, term infants were less likely to be breastfed at 6 weeks if their mother felt they had not received help at home (aOR $0.45,95 \%$ CI 0.35 to 0.64 ) compared to those who felt they had received help at home for feeding problems. Mothers who reported that they were given the contact details of community support groups were more likely to be breastfeeding at 6 weeks (aOR 1.83 , 95\% CI 1.51 to 2.22 ) compared to those who reported that they were not given the contact details.

\section{Breastfeeding support in late preterm infants}

In univariable analysis, only questions 6, 7, 8, 9 and 12 from box 1 were significantly associated with breastfeeding late preterm infants at 10 days and only questions 2, 3 and 12 were significantly associated with breastfeeding at 6 weeks. In multivariable analysis, as with term infants, late preterm infants were less likely to be breastfeeding at 10 days if their mother felt they did not receive 
Table 3 Descriptive analysis* of antenatal and delivery characteristics

\begin{tabular}{|c|c|c|c|c|}
\hline \multirow{2}{*}{$\frac{\text { Variable }}{\text { Gestation }}$} & \multicolumn{2}{|c|}{ Breastfeeding at 10 days (\%) } & \multicolumn{2}{|c|}{ Breastfeeding at 6 weeks (\%) } \\
\hline & $34-36+6$ & $37+$ & $34-36+6$ & $37+$ \\
\hline N (sample size) & $365(437)$ & 9230 (11 292) & $281(365)$ & $7547(9230)$ \\
\hline \multicolumn{5}{|l|}{ Parity } \\
\hline Primiparous & 86.9 & 83.0 & 73.6 & 79.7 \\
\hline Multiparous who breastfed $<6$ weeks & 62.9 & 65.4 & 63.6 & 69.5 \\
\hline Multiparous who breastfed $>6$ weeks & 96.9 & 94.9 & 84.8 & 89.1 \\
\hline \multicolumn{5}{|c|}{ Aware of the health benefits of breastfeeding } \\
\hline No & 77.7 & 79.6 & 72.1 & 80.4 \\
\hline Yes & 88.0 & 85.1 & 75.5 & 82.1 \\
\hline \multicolumn{5}{|l|}{ Antenatal feeding intention } \\
\hline Breastfeeding & 90.9 & 88.2 & 82.4 & 84.7 \\
\hline Infant formula & 68.3 & 39.2 & 31.6 & 54.4 \\
\hline Combination feed & 75.6 & 81.6 & 58.2 & 74.5 \\
\hline Not decided & 69.8 & 69.8 & 61.0 & 72.8 \\
\hline \multicolumn{5}{|c|}{ Knew other mothers with young infants during pregnancy and their feeding methods } \\
\hline Mothers who formula fed & 79.6 & 74.9 & 59.6 & 75.5 \\
\hline Mothers mixed fed & 85.7 & 85.3 & 80.4 & 81.1 \\
\hline Mothers who breastfed & 99.2 & 94.3 & 92.0 & 91.2 \\
\hline Did not know other mothers & 81.1 & 84.9 & 79.4 & 82.7 \\
\hline \multicolumn{5}{|l|}{ Type of birth } \\
\hline NVD & 85.0 & 85.0 & 76.1 & 82.4 \\
\hline Instrumental & 97.1 & 83.5 & 71.7 & 82.7 \\
\hline Caesarean & 83.4 & 83.1 & 75.4 & 80.3 \\
\hline \multicolumn{5}{|l|}{ Neonatal unit admission } \\
\hline No & 86.2 & 84.4 & 81.7 & 82.2 \\
\hline Yes & 84.7 & 83.2 & 67.8 & 78.6 \\
\hline \multicolumn{5}{|l|}{ Length of stay in hospital } \\
\hline$<12 \mathrm{~h}$ & 81.1 & 83.7 & 96.8 & 81.1 \\
\hline $12-24 \mathrm{~h}$ & 75.2 & 85.9 & 91.8 & 82.7 \\
\hline $1-2$ days & 87.0 & 84.4 & 76.7 & 83.2 \\
\hline 3-7 days & 87.2 & 81.7 & 75.7 & 79.5 \\
\hline$>7$ days & 85.5 & 85.8 & 67.9 & 80.2 \\
\hline Not born in hospital & 93.9 & 93.9 & 35.1 & 90.9 \\
\hline \multicolumn{5}{|l|}{ Gestation (weeks) } \\
\hline 34 & 85.6 & - & 71.8 & - \\
\hline 35 & 85.9 & - & 71.5 & - \\
\hline 36 & 85.4 & - & 78.1 & - \\
\hline 37 & - & 81.3 & - & 81.0 \\
\hline 38 & - & 83.3 & - & 83.3 \\
\hline 39 & - & 84.1 & - & 81.5 \\
\hline 40 & - & 86.1 & - & 82.4 \\
\hline 41 & - & 83.5 & - & 81.1 \\
\hline $42+$ & & 84.4 & - & 83.1 \\
\hline
\end{tabular}

${ }^{*}$ Per cent rounded to 1 decimal point (weighted). Frequencies $(n)$ are unweighted values.

NVD, normal vaginal delivery.

enough help with feeding in hospital (aOR $0.23,95 \%$ CI 0.09 to $0.60, \mathrm{p}=0.003$ ) compared to mothers who did feel they had enough help (table 5) and more likely to be breastfeeding at 10 days if their mother reported that she was given contact details for community support groups (aOR 3.14, 95\% CI 1.40 to $7.04, \mathrm{p}=0.006$ ) compared to mothers who reported that they were not given these details. The late preterm infants who reported no feeding problems at home were significantly less likely to be breastfeeding at 10 days compared to those who had experienced problems with feeding at home and had received help for them (aOR $0.08,95 \%$ CI 0.02 to 0.33 ).
In contrast to term infants, no types of breastfeeding support were associated with breastfeeding late preterm infants at 6 weeks.

\section{DISCUSSION}

Our study found a statistically significantly lower prevalence of breastfeeding at 6 weeks among late preterm infants compared to term infants. When mothers reported they had received enough help in hospital and were given contact details for support groups in the community, this was associated with a higher likelihood 
Table 4 Adjusted ORs $\nmid$ for breastfeeding support in term infants

\begin{tabular}{|c|c|c|c|c|c|c|c|c|}
\hline \multirow[b]{2}{*}{ Variable } & \multicolumn{4}{|c|}{ Breastfeeding at 10 days } & \multicolumn{4}{|c|}{ Breastfeeding at 6 weeks } \\
\hline & $\mathrm{N} \ddagger(\%) \S$ & $\mathrm{aOR}^{5}$ & $95 \% \mathrm{Cl}$ & p Value & $\mathrm{N}^{6}(\%)$ ) & $\mathrm{aOR}^{5}$ & 95\% C.I & p Value \\
\hline \multicolumn{9}{|c|}{ Q4††: Received advice on how to recognise if the infant is receiving enough milk } \\
\hline No & $5665(81.3)$ & 1 & & & $4367(80.4)$ & 1 & & \\
\hline Yes & $5536(88.0)$ & 1.24 & 1.05 to 1.46 & $0.013^{\star}$ & $4809(83.7)$ & 1.04 & 0.89 to 1.22 & 0.608 \\
\hline \multicolumn{9}{|c|}{ Q5: Received help or support in hospital for feeding problems } \\
\hline Help received & $3052(80.9)$ & 1 & & & $2380(77.1)$ & 1 & & \\
\hline No help received & 545 (72.6) & 1.07 & 0.75 to 1.53 & 0.717 & 357 (71.3) & 0.99 & 0.67 to 1.45 & 0.943 \\
\hline No problems & 7089 (86.4) & 1.57 & 1.29 to 1.91 & $<0.001^{\star \star \star}$ & 5973 (83.9) & 1.27 & 1.05 to 1.53 & $0.015^{\star}$ \\
\hline Not born in hospital & 502 (89.4) & 0.51 & 0.24 to 1.09 & 0.082 & 447 (88.8) & 1.18 & 0.56 to 2.47 & 0.660 \\
\hline \multicolumn{9}{|c|}{ Q6: Received enough help and support in hospital } \\
\hline Yes & 7891 (86.3) & 1 & & & $6636(83.4)$ & 1 & & \\
\hline No & $2795(78.2)$ & 0.61 & 0.50 to 0.74 & $<0.001^{\star \star *}$ & $2064(76.0)$ & 0.75 & 0.62 to 0.90 & $0.003^{\star *}$ \\
\hline Not born in hospital & $502(89.4)$ & 1.00 & & & 447 (88.8) & 1.00 & & \\
\hline \multicolumn{9}{|c|}{ Q7: Received contact details of community support groups for breastfeeding } \\
\hline No & $2818(71.6)$ & 1 & & & $1812(74.5)$ & 1 & & \\
\hline Yes & 8408 (88.3) & 2.24 & 1.86 to 2.68 & $<0.001^{* \star *}$ & 7366 (83.9) & 1.83 & 1.51 to 2.22 & $<0.001^{\star \star \star}$ \\
\hline \multicolumn{9}{|c|}{ Q8: Aware of the National Breastfeeding Helpline } \\
\hline No & $3550(77.3)$ & 1 & & & $2596(75.9)$ & 1 & & \\
\hline Yes & $7675(87.3)$ & 1.29 & 1.08 to 1.53 & $0.004^{\star *}$ & $6581(75.2)$ & 1.01 & 0.85 to 1.21 & 0.884 \\
\hline \multicolumn{9}{|c|}{ 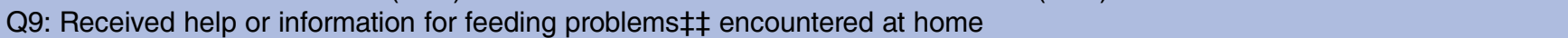 } \\
\hline Yes & $3433(89.6)$ & 1 & & & $3023(81.2)$ & 1 & & \\
\hline No & $673(75.3)$ & 0.58 & 0.42 to 0.80 & $0.001^{* *}$ & $492(64.6)$ & 0.45 & 0.35 to 0.64 & $<0.001^{\star * *}$ \\
\hline No problems & 7175 (82.8) & 0.62 & 0.50 to 0.77 & $<0.001^{* * *}$ & 5707 (84.0) & 1.26 & 1.04 to 1.52 & $0.018^{*}$ \\
\hline \multicolumn{9}{|c|}{ Q10: Used support from community support groups } \\
\hline No & $9588(83.3)$ & 1 & & & $7721(81.9)$ & 1 & & \\
\hline Yes & $1702(89.4)$ & 1.30 & 1.01 to 1.68 & $0.043^{*}$ & $1509(82.7)$ & 1.22 & 0.97 to 1.53 & 0.086 \\
\hline \multicolumn{9}{|c|}{ Q11:Used support from healthcare professionals } \\
\hline No & 2807 (87.2) & 1 & & & $2403(86.6)$ & 1 & & \\
\hline Yes & 8483 (83.3) & 0.63 & 0.50 to 0.79 & $<0.001$ & $6827(80.2)$ & 0.71 & 0.57 to 0.88 & $0.002^{\star *}$ \\
\hline \multicolumn{9}{|c|}{ 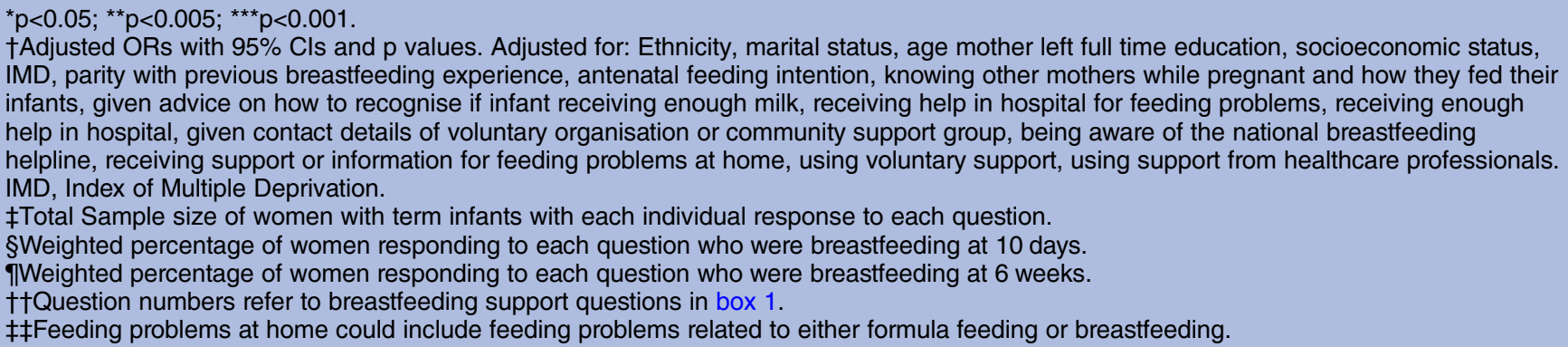 } \\
\hline
\end{tabular}

of breastfeeding in late preterm and term infants at 10 days and also term infants at 6 weeks. Successfully breastfeeding term infants at 10 days was also associated with being given advice to recognise if the infant was receiving enough milk, awareness of the national breastfeeding helpline and using community support groups.

Strengths of this study include the use of a national, population-based survey. The analysis employed survey weights which allowed for non-response and oversampling of mothers from the lowest quintile of the IMD ensuring adequate representation of this group. Using IFS data enabled simultaneous evaluation of a wide range of breastfeeding support among late preterm and term infants. As such, this study is one of the first to compare effectiveness of support between these two groups thereby addressing a gap in current literature. However, it is of note that the original survey findings are now 5 years old. A further strength is measuring outcomes at both 10 days and 6 weeks to identify support factors impacting on clinically important postnatal time points. The most rapid decline in breastfeeding rates occurs in the first 10 days after birth, ${ }^{17}$ indicating that breastfeeding support could have the most to offer mothers during that time. The risk of recall bias was limited as the questionnaire was intended for when the infant was 6 weeks old. However, given the sensitive and emotive nature of breastfeeding duration, responses may have been influenced by a socially desirable response bias with mothers perhaps overestimating the length of time they achieved breastfeeding, or underplaying the support received. The IFS questionnaire is long (150 questions) potentially presenting a challenge for a parent with a newborn infant. This may have introduced a bias in those who may have been more likely to 
Table 5 Adjusted ORs $\uparrow$ for breastfeeding support in late preterm infants

\begin{tabular}{|c|c|c|c|c|c|c|c|c|}
\hline \multirow[b]{2}{*}{ Variable } & \multicolumn{4}{|c|}{ Breastfeeding at 10 days } & \multicolumn{4}{|c|}{ Breastfeeding at 6 weeks } \\
\hline & $\mathrm{N \neq}(\%) \S$ & $\mathrm{aOR}^{8}$ & $95 \% \mathrm{Cl}$ & p Value & $\mathrm{N}^{12}(\%) \uparrow$ & $\mathrm{aOR}^{8}$ & 95\% C.I & p Value \\
\hline \multicolumn{9}{|c|}{ Q6††: Received enough help and support with feeding in hospital } \\
\hline Yes & $321(89.2)$ & 1 & & & $277(77.0)$ & 1 & & \\
\hline No & $102(73.6)$ & 0.23 & 0.09 to 0.60 & $0.003^{\star \star}$ & $76(71.0)$ & 0.57 & 0.24 to 1.33 & 0.190 \\
\hline Not born in hospital & $12(98.0)$ & 2.73 & 0.25 to 29.9 & 0.411 & $11(66.3)$ & 0.27 & 0.07 to 1.05 & 0.059 \\
\hline \multicolumn{9}{|c|}{ Q7: Received contact details for community support groups for breastfeeding } \\
\hline No & $140(73.9)$ & 1 & & & $102(69.2)$ & 1 & & \\
\hline Yes & $293(91.3)$ & 3.14 & 1.40 to 7.04 & $0.006^{\star \star}$ & 260 (77.9) & 1.86 & 0.87 to 3.95 & 0.106 \\
\hline \multicolumn{9}{|c|}{ 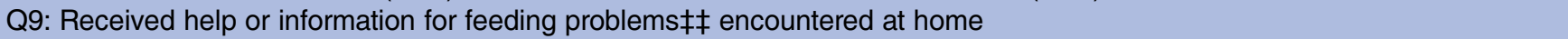 } \\
\hline Had help & $103(97.6)$ & 1 & & & $100(81.2)$ & 1 & & \\
\hline No help given & $31(86.6)$ & 0.41 & 0.04 to 4.08 & 0.449 & 25 (76.9) & 0.86 & 0.18 to 3.99 & 0.845 \\
\hline No problems & $302(81.8)$ & 0.08 & 0.02 to 0.33 & $0.001^{\star *}$ & $239(73.1)$ & 0.69 & 0.29 to 1.64 & 0.402 \\
\hline \multicolumn{9}{|c|}{ 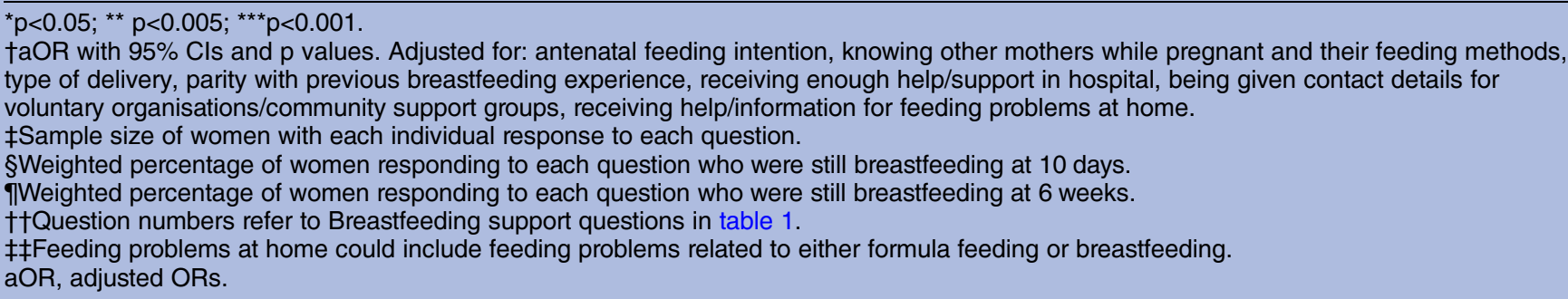 } \\
\hline
\end{tabular}

respond. In addition, this study investigated the association between the parental perception of support given, rather than the actual support given and was limited by the wording of the original survey questions. For example while we have shown that receiving enough help with breastfeeding in hospital is associated with breastfeeding term and late preterm infants at 10 days, it was not possible to further delineate what support had been received by those who felt they had received 'enough'. However, it may be the perception that breastfeeding support is available combined with the provision of information in case of feeding problems, is important in enabling successful breastfeeding. Finally, although the overall sample size was large $(n=15104)$, a further potential limitation is the relatively small number of late preterm infants in the study $(\mathrm{n}=579)$.

Although a large number of potential confounding factors were included in the analysis, it is not possible to exclude residual confounding by unmeasured factors, for example medical problems of mother or infant. Another limitation is the likely heterogeneous nature of the breastfeeding groups, ranging from primarily breastfed infants to infants receiving minimal breastmilk. However, it was not possible to subdivide by amount of breastmilk being received. Nonetheless, given the current low rates of breastfeeding in the UK, establishing interventions which may improve any breastfeeding remains important.

Previous studies have also identified late preterm infants as having lower rates of breastfeeding than term infants ${ }^{14}{ }^{15}$ which is likely due to a combination of factors, including delayed lactogenesis ${ }^{34}$ and physiological immaturity resulting in a reduced sucking ability. ${ }^{35}{ }^{36}$ While late preterm infants often do not fit criteria for NNU admission, postnatal wards may not offer the additional support required to ensure successful breastfeeding. The Infant Feeding Survey report ${ }^{17}$ found the main reasons women stopped breastfeeding in the first weeks after birth were due to the baby not sucking, the mother having painful breasts or feeling she had insufficient milk. For women who stopped in the first 2 weeks, the factors they felt could have helped them breastfeed for longer included more support and guidance from hospital staff, midwives and families (23\% of respondents), if the baby had latched on the breast easier (19\%) and if there had been less pain (14\%). This study found receiving enough help in hospital was associated with breastfeeding late preterm infants at 10 days and term infants at 10 days and 6 weeks. This type of support may have been delivered via a number of different mechanisms. Both Oakley et $a l^{33}$ and Henderson and Redshaw ${ }^{32}$ had previously noted associations between initial midwifery support and breastfeeding at 6 weeks and 4 months respectively, support which is likely to have taken place in the hospital. Renfrew et $a l^{25}$ found all forms of 'breastfeeding support' to have a positive impact on breastfeeding in term infants. Those results are borne out by the wide variety of support associated with breastfeeding at 10 days in the term infants in our study. The vast majority of previous studies only included healthy term infants although Henderson and Redshaw ${ }^{32}$ observed lower rates of breastfeeding initiation in preterm than term infants $(77.2 \%$ vs $80.5 \%)$. However, they did not differentiate between the two groups when analysing the impact of breastfeeding support.

In this study, term infants whose mothers used support from health professionals were less likely to be 
breastfeeding at 10 days and 6 weeks. This finding is in contrast to existing evidence such as the Cochrane review, ${ }^{25}$ which found that breastfeeding support was associated with increasing breastfeeding duration. However, our result is likely to be confounded by the fact that those experiencing feeding problems are more likely to cease breastfeeding, but also more likely to be accessing professional support-41\% of those using health professional support had also stated they had experienced feeding problems in hospital, compared to only $5 \%$ who had not used this support. Late preterm and term infants were less likely to be breastfeeding at 10 days if they had not experienced feeding problems at home. However, this may be the result of mothers who stopped breastfeeding early, potentially prior to discharge from hospital as mothers were classified as having initiated breastfeeding, even if the infant only had one breastfeed after birth. Among the late preterm infants, $37 \%$ of those with no feeding problems had already stopped breastfeeding by 5 days, compared to only $7 \%$ of those who had help for feeding problems. By 6 weeks of age, term infants were more likely to be breastfeeding if they had not encountered feeding problems at home as this analysis only included infants who were still breastfeeding by 10 days.

This study identified that late preterm and term infants were more likely to be breastfeeding at 10 days if their mother had received the contact details for a community support group, compared to women who did not receive these details. However, it was not possible to determine whether these women actually attended a support group or not and at what age of the infant. A cluster randomised trial ${ }^{37}$ of a policy to provide breastfeeding groups in primary care found increased provision of breastfeeding groups did not improve breastfeeding rates at 6-8 weeks for the intervention group compared to the control group. The median infant age for attending such a group in this trial was 5 weeks, which would be counter to the fact that receiving this information was associated with breastfeeding at 10 days in our study. It is of note, however, that the trial was introducing breastfeeding support groups into relatively deprived areas of Scotland which may have impacted the results as it is well recognised that increasing deprivation is associated with lower rates of breastfeeding.

Previous studies have demonstrated strong associations between sociodemographic factors and breastfeeding $^{21} 22$ 31-33 38 which our study replicated among term infants. Demirci $e t a l,{ }^{23}$ with a large sample of 7012 late preterm infants found breastfeeding initiation was associated with maternal education, marital status and ethnicity. In our study no sociodemographic characteristics were statistically significant in late preterm infants which was in contrast to the findings for term infants. Although our sample size was relatively small, and may not have had sufficient power to identify particular effects, this finding may also suggest that sociodemographic factors may be less relevant in determining continuation of breastfeeding in late preterm infants compared to term infants.

Breastfeeding rates in the UK have a long way to go before reaching the WHO recommendations and it is clear that providing breastfeeding support will be part of this. This study has identified that while a similar proportion of term and late preterm infants initiated breastfeeding, the late preterm infants were significantly less likely to be breastfeeding by 6 weeks. Relatively simple breastfeeding support methods, such as the provision of contact details for community breastfeeding support groups has been demonstrated by this study as being associated with successful breastfeeding for term and late preterm infants. Mothers who felt they had received enough help and support with breastfeeding while in hospital were also more likely to be breastfeeding late preterm and term infants at 10 days. Support for breastfeeding should be at the forefront of maternity practice in hospital, and community services need to ensure that basic information on how to obtain help and support is visibly given to all mothers while instituting a culture of easily accessible breastfeeding support for mothers if and when they need it.

In conclusion, our study found breastfeeding support to be positively associated with breastfeeding at 10 days in late preterm and term infants and at 6 weeks in term infants, in particular receiving the contact details for community support groups and receiving enough help with breastfeeding in hospital. Increasing rates of breastfeeding should be a public health priority globally, but especially in the UK where exclusive breastfeeding rates are particularly low. Late preterm infants are likely to require additional support, given their even lower rates of breastfeeding. Further research is required on breastfeeding continuation in late preterm infants in order to understand the complex interplay of factors determining breastfeeding success for this population.

Twitter Follow Sarah Rayfield at @RayfieldSarah

Contributors All authors conceived the study and contributed to the design of the study. SR conducted the analysis with guidance from MAQ. All authors were involved in the interpretation of the data. SR wrote the initial draft of the manuscript, and all authors contributed to revising consecutive drafts. All authors approved the final version of the manuscript. All authors had full access to all of the data in the study and can take responsibility for the integrity of the data and the accuracy of the data analysis.

Funding This paper reports on an independent study which is fully funded by the Policy Research Programme in the Department of Health (Grant No. 108/ 001/PRU). SR is salaried by Oxford University Hospitals NHS Trust and this research was conducted as part of a thesis in partial fulfilment for the MSc in Global Health Science.

Disclaimer The views expressed are not necessarily those of the Department. The funder had no role in: the design and conduct of the study; the analysis and interpretation of the data; and the drafting of the paper and decision to submit the paper for publication.

Competing interests None declared.

Provenance and peer review Not commissioned; externally peer reviewed. 
Data sharing statement No additional data are available.

Open Access This is an Open Access article distributed in accordance with the terms of the Creative Commons Attribution (CC BY 4.0) license, which permits others to distribute, remix, adapt and build upon this work, for commercial use, provided the original work is properly cited. See: http:// creativecommons.org/licenses/by/4.0/

\section{REFERENCES}

1. Raju TN, Higgins RD, Stark AR, et al. Optimizing care and outcome for late-preterm (near-term) infants: a summary of the workshop sponsored by the National Institute of Child Health and Human Development. Pediatrics 2006;118:1207-14.

2. Wang ML, Dorer DJ, Fleming MP, et al. Clinical outcomes of near-term infants. Pediatrics 2004;114:372-6.

3. Radtke JV. The paradox of breastfeeding-associated morbidity among late preterm infants. J Obstet Gynecol Neonatal Nurs 2011;40:9-24.

4. Escobar GJ, Mccormick MC, Zupancic JA, et al. Unstudied infants: outcomes of moderately premature infants in the neonatal intensive care unit. Arch Dis Child Fetal Neonatal Ed. 2006;91:F238-44.

5. Quigley MA, Cumberland P, Cowden JM, et al. How protective is breast feeding against diarrhoeal disease in infants in 1990s England? A case-control study. Arch Dis Child 2006;91:245-50.

6. Howie PW, Forsyth JS, Ogston SA, et al. Protective effect of breast feeding against infection. BMJ 1990;300:11-16.

7. Kramer MS, Guo T, Platt RW, et al. Infant growth and health outcomes associated with 3 compared with 6 mo of exclusive breastfeeding. Am J Clin Nutr 2003;78:291-5.

8. Kramer MS. "Breast is best": the evidence. Early Hum Dev 2010;86:729-32.

9. World Health Organisation. Effect of breastfeeding on infant and child mortality due to infectious diseases in less developed countries: a pooled analysis. WHO collaborative study team on the role of breastfeeding on the prevention of infant mortality. Lancet 2000;355:451-5.

10. Duijts L, Jaddoe VW, Hofman A, et al. Prolonged and exclusive breastfeeding reduces the risk of infectious diseases in infancy. Pediatrics 2010;126:e18-25.

11. Lopez-Alarcon M, Villalpando S, Fajardo A. Breast-feeding lowers the frequency and duration of acute respiratory infection and diarrhea in infants under six months of age. J Nutr 1997; $127: 436-43$.

12. Cushing $\mathrm{AH}$, Samet JM, Lambert WE, et al. Breastfeeding reduces risk of respiratory illness in infants. Am J Epidemio 1998;147:863-70.

13. Quigley MA, Hockley C, Carson C, et al. Breastfeeding is associated with improved child cognitive development: a population-based cohort study. J Pediatr 2012;160:25-32.

14. Donath SM, Amir LH. Effect of gestation on initiation and duration of breastfeeding. Arch Dis Child Fetal Neonatal Ed 2008;93:F448-50.

15. Ayton J, Hansen E, Quinn S, et al. Factors associated with initiation and exclusive breastfeeding at hospital discharge: late preterm compared to 37 week gestation mother and infant cohort. Int Breastfeed J 2012;7:16.

16. Department of Health. Infant feeding recommendation. London. 2003. [14th September 2014]. Http://Webarchive.Nationalarchives. Gov.Uk/+/Www.Dh.Gov.Uk/En/Publicationsandstatistics/Publications/ Publicationspolicyandguidance/Dh_4097197.

17. Health and Social Care Information Centre Ir. Infant Feeding Survey 2010. Health and Social Care Information Centre, 2012. 20 November 2012; Report No.: 1.
18. Agboado G, Michel E, Jackson E, et al. Factors associated with breastfeeding cessation in nursing mothers in a peer support programme in Eastern Lancashire. BMC Pediatr 2010;10:3.

19. Santorelli G, Petherick E, Waiblinger D, et al. Ethnic differences in the initiation and duration of breast feeding-results from the born in bradford birth cohort study. Paediatr Perinat Epidemiol 2013;27:388-92.

20. Al-Sahab B, Lanes A, Feldman M, et al. Prevalence and predictors of 6-month exclusive breastfeeding among Canadian women: a national survey. BMC Pediatr 2010;10:20.

21. Tarrant RC, Younger KM, Sheridan-Pereira M, et al. The prevalence and determinants of breast-feeding initiation and duration in a sample of women in Ireland. Public Health Nutr 2010;13:760-70.

22. Van Rossem L, Oenema A, Steegers EA, et al. Are starting and continuing breastfeeding related to educational background? The generation R study. Pediatrics 2009;123:e1017-27.

23. Demirci JR, Sereika SM, Bogen D. Prevalence and predictors of early breastfeeding among late preterm mother-infant dyads. Breastfeed Med 2013;8:277-85.

24. World Health Organisation / UNICEF. Protecting, promoting and supporting breastfeeding: the special role of maternity services. Geneva: World Health Organisation, 1989

25. Renfrew MJ, Mccormick FM, Wade A, et al. Support for healthy breastfeeding mothers with healthy term babies. Cochrane Database Syst Rev 2012;5:CD001141.

26. Renfrew MJ, Dyson L, Mccormick F, et al. Breastfeeding promotion for infants in neonatal units: a systematic review. Child Care Health Dev 2010;36:165-78.

27. Health and Social Care Information Centre Ir. Infant Feeding Survey 2010: Appendix E. Survey Documents. Health and Social Care Information Centre, 2012. 20 November 2012; Report No.

28. World Health Organisation. Indicators for assessing infant and young child feeding practices: part 1-definitions. Geneva: World Health Organisation, 2008.

29. Office for National Statistics. The national statistics socioeconomic classification: origins, development and use. The Office for National Statistics, 2005.

30. Department for Communities and Local Government. English Indices of Deprivation 2010. Neigbourhoods Statistical Release. 2011.

31. Donnan PT, Dalzell J, Symon A, et al. Prediction of initiation and cessation of breastfeeding from late pregnancy to 16 weeks: the Feeding Your Baby (FYB) cohort study. BMJ Open 2013;3:pii: e003274.

32. Henderson J, Redshaw M. Midwifery factors associated with successful breastfeeding. Child Care Health Dev. 2011;37:744-53.

33. Oakley LL, Henderson J, Redshaw M, et al. The role of support and other factors in early breastfeeding cessation: an analysis of data from a maternity survey in England. BMC Pregnancy Childbirth 2014;14:88.

34. Dewey KG. Maternal and fetal stress are associated with impaired lactogenesis in humans. J Nutr 2001;131:3012S-15S.

35. Meier PP, Furman LM, Degenhardt M. Increased lactation risk for late preterm infants and mothers: evidence and management strategies to protect breastfeeding. J Midwifery Womens Health. 2007;52:579-87.

36. Hellmeyer L, Herz K, Liedtke B, et al. The underestimation of immaturity in late preterm infants. Arch Gynecol Obstet 2012;286:619-26.

37. Hoddinott P, Britten J, Prescott GJ, et al. Effectiveness of policy to provide breastfeeding groups (BIG) for pregnant and breastfeeding mothers in primary care: cluster randomised controlled trial. BMJ 2009;338:a3026.

38. Oakley LL, Renfrew MJ, Kurinczuk JJ, et al. Factors associated with breastfeeding in England: an analysis by primary care trust. BMJ Open 2013;3:pii: e002765. 